\title{
Spectrum of CT findings in gall bladder carcinoma patients in north Indian population
}

\author{
Singh $\mathbf{P}^{1}$, Kaur $\mathbf{N}^{2}$, Kaur $\mathbf{M}^{3}$ \\ ${ }^{1}$ Dr. Pushpinder Singh, Assistant Professor, Radiodiagnosis, Adesh Institute Of Medical Sciences \& Research Bathinda, \\ ${ }^{2}$ Dr. Navkiran Kaur, Professor \& Head, Radiodiagnosis, Govt. Medical College, Patiala, ${ }^{3}$ Dr. Mandeep Kaur, Assistant \\ Professor, Pharmacology, Adesh Institute Of Medical Sciences \& Research Bathinda, Punjab, India.
}

Address for Correspondence: Dr. Mandeep Kaur, 307 B-Block, Adesh Institute Of Medical Sciences \& Research Bathinda. Email- mandeeplobana1@yahoo.com

\begin{abstract}
Background: Gallbladder carcinoma is the most common malignancy of the biliary tract and ranks fifth amongst gastrointestinal cancers. In Asia, increased frequency of gall bladder carcinoma is seen in north Indian Females. Method: A prospective study was carried out on 60 patients of gall bladder (GB) mass who were selected from OPD and wards of the hospital. CT scan of these patients was done using Siemens Somatom Emotion 6 slice machine. Results: Among the 60 patients of GB mass included in this study, 46 patients were diagnosed as gall bladder carcinoma based on the multidetector computed tomographic findings and its correlation with histopathology. Out of 46 patients 30 were females and 16 were males. Infiltrating masses were detected in 28 patients, intraluminal polypoidal masses were detected in 10 patients while eight patients presented with mural thickening of the gall bladder wall. Conclusion: We conclude that multidetector CT is the diagnostic tool of choice in the detection of gall bladder carcinoma and extension of tumour to distant sites.
\end{abstract}

Keywords: Gall bladder, Carcinoma, Gall bladder masses, Computed tomography

\section{Introduction}

Gallbladder cancer is the most common malignancy of the biliary tract, representing $80 \%-95 \%$ of biliary tract cancers worldwide [1]. It ranks fifth among gastrointestinal cancers [2]. In India, gall bladder cancer is more prevalent in north and north-eastern regions of the country while Southern India has low incidence rate in both the sexes $[3,4,5]$. Gall bladder cancer is more frequent in elderly people with female preponderance [5]. This cancer develops rapidly and silently with early diagnosis of gallbladder carcinoma difficult because most patients present with nonspecific findings of right upper quadrant pain, malaise, weight loss, jaundice, anorexia, and vomiting.

This presentation is often confused with symptomatic cholelithiasis or chronic cholecystitis. Gallbladder carcinoma may present as mass completely occupying

Manuscript received: $5^{\text {th }}$ May 2017

Reviewed: $16^{\text {th }}$ May 2017

Author Corrected: $24^{\text {th }}$ May 2017

Accepted for Publication: $31^{\text {st }}$ May 2017 or replacing the gallbladder lumen (in $40-65 \%$ of cases), focal or diffuse asymmetric gallbladder wall thickening (in $20-30 \%$ of cases) or an intraluminal polypoid lesion (in $15-25 \%$ of cases $[6,7,8,9]$. Associated findings may be cholelithiasis, bile duct dilatation, invasion of the adjacent structures, distant metastasis other than those in the liver and porcelain gallbladder. Ultrasound is often the initial and most commonly used imaging modality for suspected gallbladder pathology because of its low cost and widespread availability. Accurate diagnosis may be difficult using sonography because thickening of the gallbladder wall is nonspecific finding.

However, CT has become popular for evaluating the acute abdomen and often has been found as first modality to detect and characterize gallbladder wall thickening and other pathologies [10]. It may be used as an adjunct to an inconclusive sonography or for staging of disease. 


\section{Material \& Methods}

Study Design: This was a hospital based prospective, observational and non-interventional study.

CT Technique: Siemens Somatom Emotion 6 slice CT machine was used in the study. The detail of the procedure was explained to the patient. A female attendant was instructed to be present during the procedure in case of female patients. A written consent was obtained from each patient after explaining the possibility of contrast reaction. Nonionic iodine contrast $300 \mathrm{mg}$ was used. Orally water soluble iodinated contrast (Diatrizoate Meglumine and Diatrizole sodium injection USP) diluted in $700 \mathrm{ml}$ to $1000 \mathrm{ml}$ of water was given before the CT.

Then patient was placed on the gantry table in supine position with both arms above the head, $8 \mathrm{~mm} \times 8 \mathrm{~mm}$ sections were obtained. Contrast scan was obtained by injecting $100 \mathrm{ml}$ iodinated contrast at the rate of $2-3 \mathrm{ml}$ per second using a pressure injector via $20 \mathrm{G}$ angiocath place in antecubital vein. Precontrast study of the gall bladder fossa was performed initially followed by the postcontrast study of the gall bladder fossa. Triphasic CT scan was done in cases where differentiation from hepatocellular carcinoma was difficult.

Participants: The study enrolled sixty patients with clinically/sonologically suspected gall bladder mass in any age group in both males and females. Further patient was provisionally diagnosed by contrast enhanced computed tomography as carcinoma of the gall bladder and final diagnosis was confirmed histopathologically.

Inclusion criteria: Patients with clinically suspected gall bladder disease/mass confirmed on USG in any age group in both males and females were included in the study.

Exclusion criteria: Patients presenting with traumatic GB fossa lesions were not included in the study.

Data Source: The prospective study was carried out at Government Rajindra Medical College and Hospital Patiala, Punjab from Jan 2013 to Oct. 2014. Approval for conducting this study was obtained from Institutional review board and informed consent of the study was taken from the patients.

Bias: Each patient was examined for any previous biliary disease, history of jaundice, cholelithiasis. Fertile female with more than forty years age and history of long standing biliary disease were the bias factors.

Statistical analysis: The results were analyzed using specificity, sensitivity, positive predictive value and negative predictive value as statistical measures.

\section{Results}

Among the sixty patients included in this study there were forty one females and nineteen males with female to male ratio of 2.16:1. Their ages ranged from 32 to 84 years. Maximum number of patients was in 51-60 years age group (36.67\%). Mean age in our study was 55.73 years. Majority of the patients $(85 \%)$ presented abdominal pain as predominant clinical symptom followed by abdominal mass (45\%). Sixteen patients (26.7\%) presented with marked weight loss and twelve patients $(20 \%)$ with abdominal distension.

When CT scan was done on these 60 cases in our study, 31 cases reported with GB fossa mass, 10 with polypoidal mass and 14 with focal/ local GB wall thickening. One case in our study was of adenomyomatosis. No obvious finding was seen in four cases. These four cases were diagnosed as polyp $<10 \mathrm{~mm}$ on USG. On histopathological diagnosis, out of these 60 cases, 49 cases were found to be malignant as shown in Table-1.

Table-1: Comparison of CT findings with histopathology.

\begin{tabular}{|c|c|c|}
\hline Type of Leison & Malignant Cases & Benign Cases \\
\hline GB* fossa mass & 31 & 0 \\
\hline Localized/polypoidal Mass & 10 & 6 \\
\hline Wall thickening-focal/diffuse & 08 & 1 \\
\hline Adenomyomatosis & 0 & 0 \\
\hline
\end{tabular}

*GB= Gall Bladder 
Out of the total 49 cases of masses in the gall bladder or GB fossa on CT scan, liver infiltration was seen in 37 (75.5\%), duodenum, pancreas and omental involvement in $21(42.9 \%)$, lymph node metastasis in $26(53 \%)$, intra hepatic biliary dilatation in $12(24.5 \%)$ cases. Cholelithiasis was seen in 28 patients $(57.1 \%)$, ascites and pleural effusion was seen in 15 (30.6\%) and peritoneal involvement was seen in 10 cases $(20.4 \%)$. On further histopathological evaluation, it was found out that out of 31 cases of GB fossa mass detected on CT scan (fig.1a, 1b), 28 cases were of gall bladder carcinoma, two cases were of hepatocellular carcinoma and one case was of cholangiocarcinoma. The sensitivity of CT in the diagnosis of gall bladder carcinoma (GB fossa mass) was found to be $100 \%$ with specificity of $90 \%$, Positive Predictive Value of $93.55 \%$ and negative predictive value of $100 \%$.

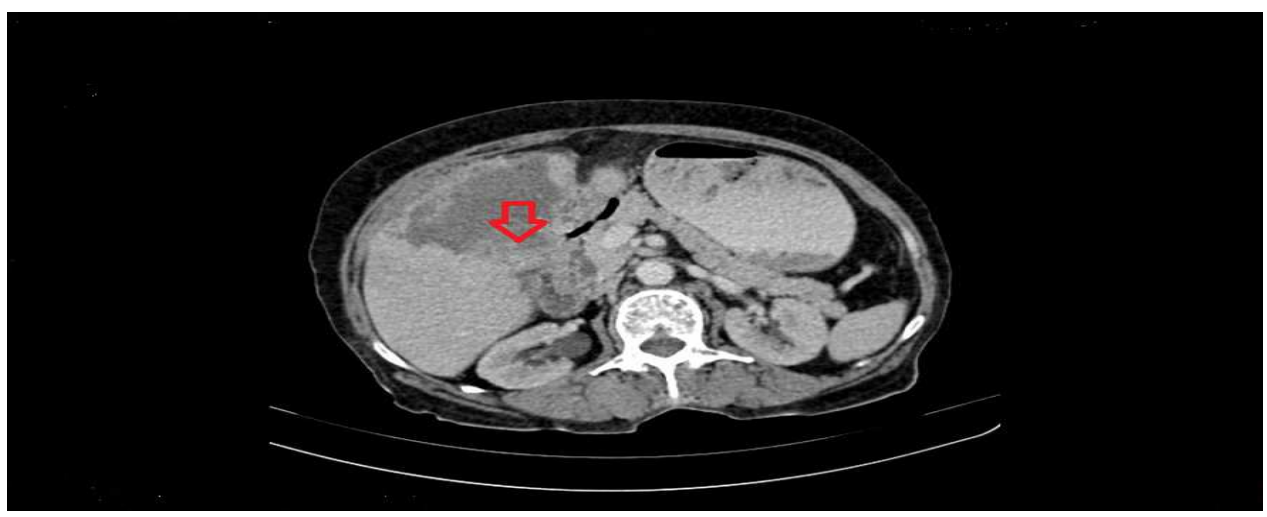

Fig-1(a): Gall bladder fossa mass infiltrating into liver

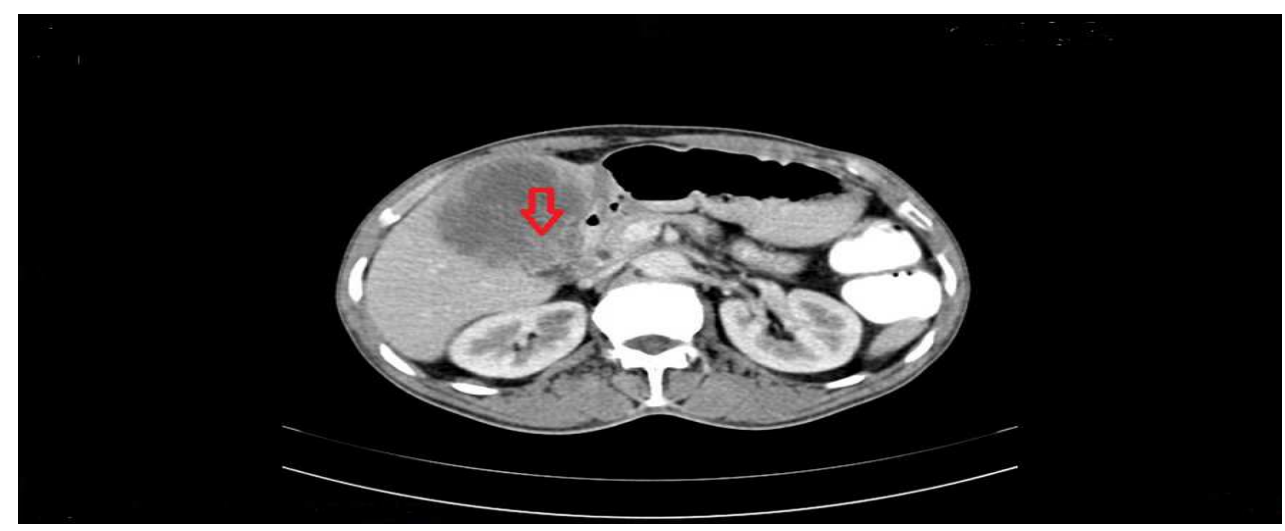

Fig.-1b: Gall bladder fossa mass infiltrating into liver

Out of 10 cases of polypoidal mass detected on CT, all ten cases were found to be of gall bladder carcinoma on histopathology (fig. 2). The sensitivity of CT in the diagnosis of gall bladder carcinoma (localized/polypoidal mass) was $100 \%$ with specificity of $100 \%$, positive predictive value of $100 \%$ and negative predictive value of $100 \%$.

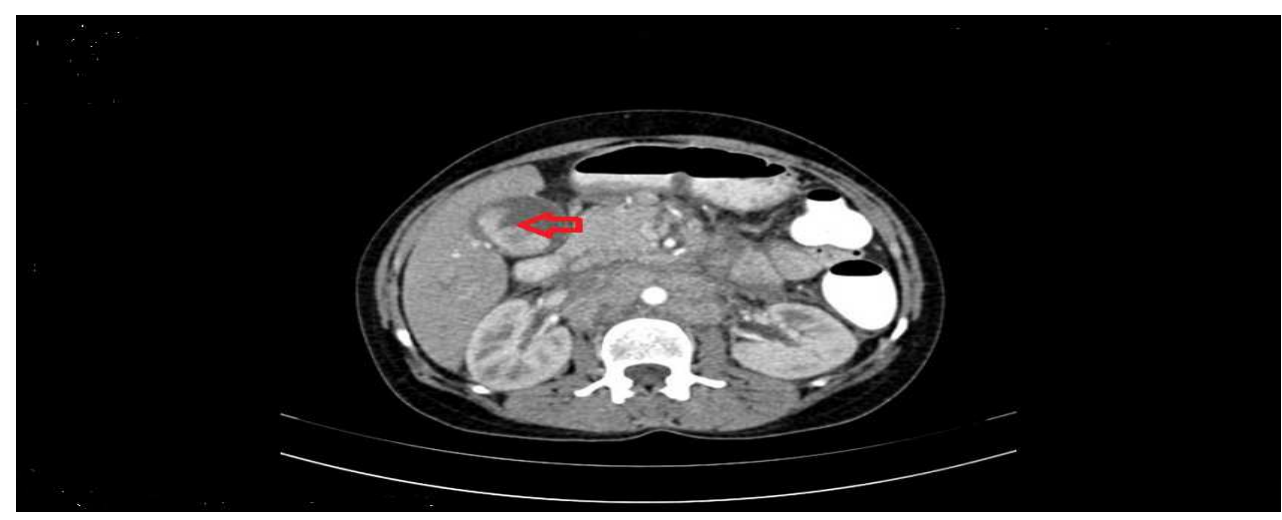

Fig.-2: Polypoidal mass in gall bladder, proved out to be adenocarcinoma on histopathology 
Out of 14 cases with focal or diffuse wall thickening detected on CT, Eight cases were found suspicious of malignancy on CT scan, later on all these eight cases were found to be gall bladder carcinoma on histopathology(fig.- 3, 4a, 4b). The sensitivity of CT in the diagnosis of gall bladder carcinoma (wall thickening focal/diffuse) was $100 \%$ with specificity of $100 \%$, positive predictive value of $100 \%$ and negative predictive value of $100 \%$.

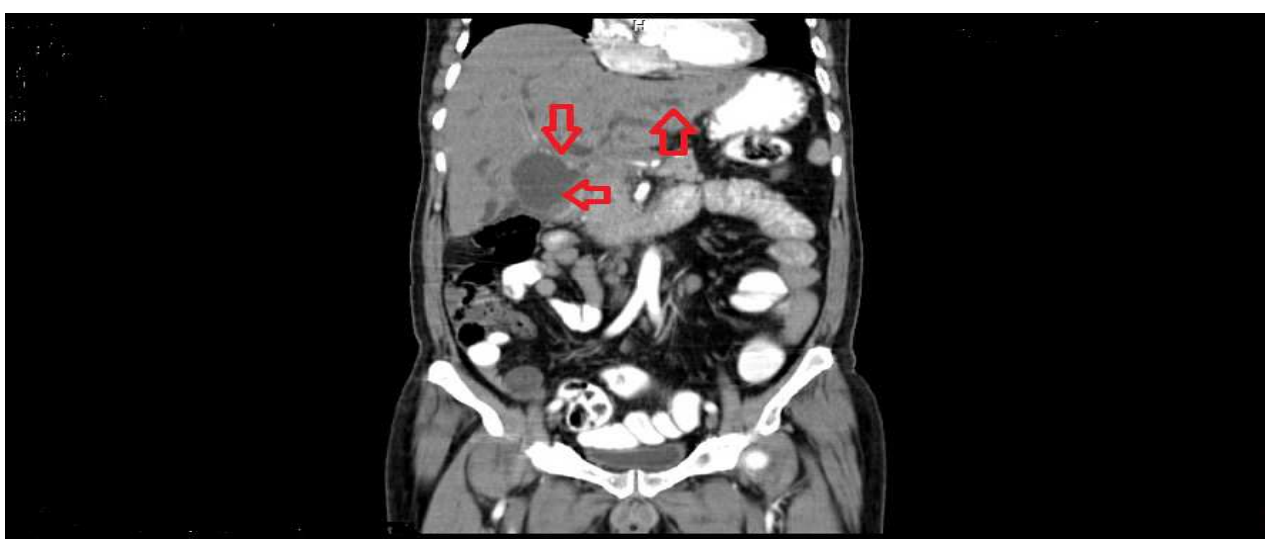

Fig.-3: Diffuse gall bladder wall thickening dilated IHBR (Intra Hepatic Biliary Radicals), later proved out to be adenocarcinoma on histopathology

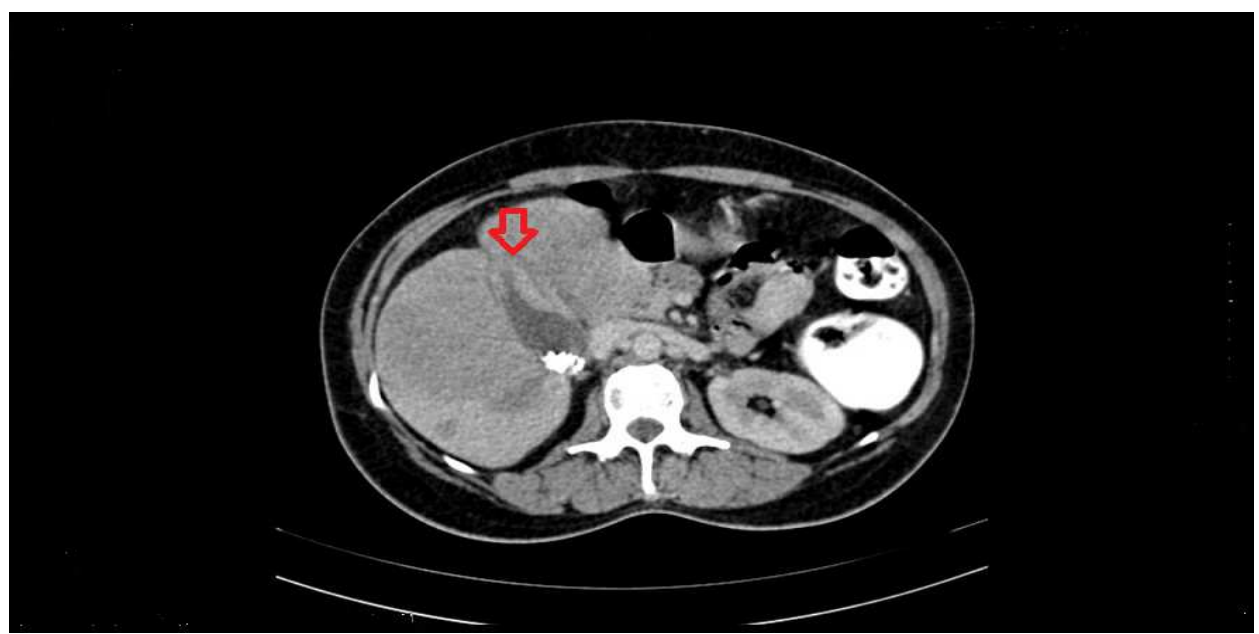

Fig.-4(a): - Case of focal wall thickening and cholelithiasis with SOLs (Space Occupying Lesions) liver, later proved out to be adenocarcinoma of gall bladder on histopathology

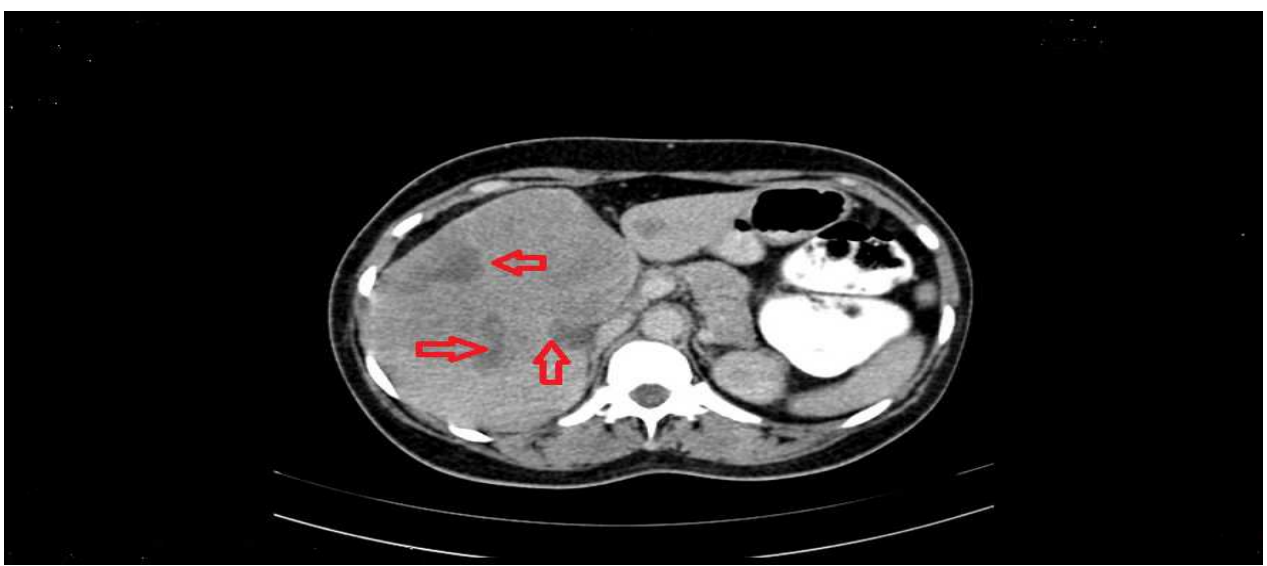

Fig.-4(b): Case of focal wall thickening and cholelithiasis with SOLs(Space Occupying Lesions) liver, later proved out to be adenocarcinoma of gall bladder on histopathology 
Based upon CT findings and its histopathological correlation, 46 cases of gall bladder carcinoma were found to be present in our study out of 60 cases. Out of these 46 cases, 30 were females and 16 were males with female to male ratio of 1.87:1. Out of 46 cases of gall bladder carcinoma, maximum numbers of patients were in 51-60 years age group $(50 \%)$. Second highest incidence was in 61-70 years age group (23.9\%) followed by $41-50$ years age group (10.9\%).

\section{Discussion}

There were three patterns of findings seen in gall bladder fossa mass on CT. Out of the total 49 malignant cases of masses in the gall bladder or GB fossa, $31(63.3 \%)$ cases presented with a mass in GB fossa, a localized/polypoidal growth within GB was appreciated in $10(20.4 \%)$ cases.

Wall thickening of varying degrees either focal or diffuse was detected in $8(16.3 \%)$ cases. GB fossa mass was the common presentation with maximum number of patients (37) showing liver infiltration. Wall thickening of varying degrees either focal or diffuse was the least presentation in our study. These findings were in accordance with the study conducted by Gore et al (2002) and Hagga et al (2003) and Afifi et al (2012) where the least common presentation was wall thickening of varying degrees either focal or diffuse and the most common presentation was a sub-hepatic mass replacing or obscuring the gall bladder with invasion of the adjacent liver[11,12,13].

Gore et al (2002) study reported intraluminal polyploidal mass in the GB in approximately $25 \%$ cases whereas George et al (2007) study reported intraluminal polyploidal mass in $10(20 \%)$ of cases[11,14]. These polypoidal intraluminal masses showed homogenous enhancement on the contrast-enhanced images. Areas of necrosis or calcification are usually not seen in polypoidal gallbladder carcinoma. Our results were nearly comparable to the above studies. This finding was seen in $20.4 \%$ of our cases.

In the study conducted by George et al (2007) focal or diffuse wall thickening was appreciated in 12 (24\%) cases and in our study the focal/diffuse wall thickening was observed in $16.3 \%$ cases[14].

Out of the total $49(81.7 \%)$ cases of malignant origin masses in the gall bladder or GB fossa, on CT scan, liver infiltration was seen in 37 cases $(75.5 \%)$. Duodenum, pancreas and omental involvement was seen in 21 cases $(42.9 \%)$, lymph node metastasis in 26 cases $(53 \%)$, intra hepatic biliary dilatation in 12 cases (24.5\%). cholelithiasis in 28 patients $(57.1 \%)$, ascites and pleural effusion in 15 cases $(30.6 \%)$ and peritoneal involvement was seen in 10 cases (20.4\%). These findings in our study were comparable to the data reported by George et al (2007) in which infiltration into liver was seen in 36 (72\%) cases, while infiltration into the adjacent structures such as duodenum, pancreas and omentum was seen in $23(46 \%)$ cases at the time of diagnosis[14].

The lymph nodes were involved in $21(42 \%)$ patients. Obstructive jaundice with intrahepatic biliary radical dilatation was seen in $15(30 \%)$ cases and cholelithiasis in $29(58 \%)$ cases.

The overall sensitivity of CT in the diagnosis of gall bladder carcinoma was $100 \%$ with specificity of $84.62 \%$ positive predictive value of $95.92 \%$ negative predictive value of $100 \%$. So CT was better in evaluation of GB mass.

\section{Conclusion}

- Early diagnosis of gall bladder carcinoma is difficult because most of the patients present with non specific findings which are often confused with symptomatic cholelithiasisis or chronic choleycystitis.

- Gall bladder carcinoma is highly malignant tumor with poor prognosis(more than $70 \%$ cases already have metastasis at the time of diagnosis).

- Gall bladder Carcinoma is more commonly seen in elderly female with peak incidence in 50-70 years of age.

- Multidetector CT is the diagnostic tool of choice in the detection of gall bladder carcinoma and specially for staging including the extension of tumour into liver and adjacent structures as well as to distant sites including peritoneum and lymph nodes.

- Triphasic CT scan should be done in cases where differentiation from hepatocellular carcinoma is difficult.

\section{Funding: Nil, Conflict of interest: None Permission of IRB: Yes}




\section{References}

1. Rajveer Hundal, Eldon A Shaffer. Gallbladder cancer: epidemiology and outcome. Clinical Epidemiology 2014; 6:99-109. doi: 10.2147/ CLEP. S37357.

2. Nandakumar A, Gupta P, Gangadharan P, Visweswara R, Parkin D. Geographic pathology revisited: Development of an atlas of cancer in India. International Journal of Cancer. 2005;116(5):740-754. doi: $10.1002 /$ ijc. 21109

3. Devi S, Singh RK. Gall bladder cancer: a retrospective study in a tertiary care hospital experience. International journal of medical and applied sciences 2015;4(1):94-106.

4. BB Tyagi, N Manoharan, V Raina. Risk factors for gallbladder cancer : A population based case-control study in Delhi. Indian jou of Medical and paediatric oncology 2008; 29 (1)16-26. doi: 10.4103/0971-5851. 51442 .

5. Gupta S, Kori C, Kumar V, Misra S, Akhtar N. Epidemiological Study of Gallbladder Cancer Patients from North Indian Gangetic Planes-a High-Volume Centre's Experience. J Gastrointest Cancer 2016;47(1): 27-35. doi: 10.1007/s12029-015-9781-5.

6. Levy AD, Murakata LA, Rohrmann CA Jr. Gallbladder carcinoma: radiologic- pathologic correlation. Radiographics. 2001 Mar-Apr; 21(2):295314; questionnaire, 549-55.

7. Franquet T, Montes M, Ruiz de Azua Y, Jimenez FJ, Cozcolluela R. Primary gallbladder carcinoma: imaging findings in 50 patients with pathologic correlation. Gastrointest Radiol. 1991 Spring;16(2):143-8.
8. Reid KM, Ramos-De la Medina A, Donohue JH. Diagnosis and surgical management of gallbladder cancer: a review. J Gastrointest Surg. 2007 May;11 (5): 671-81.

9. Rodríguez-Fernández A, Gómez-Río M, MedinaBenítez A, Moral JV, Ramos-Font C, Ramia-Angel JM, Llamas-Elvira JM, Ferrón-Orihuela JA, Lardelli-Claret P. Application of modern imaging methods in diagnosis of gallbladder cancer. J Surg Oncol. 2006 Jun 15;93 (8): 650-64.

10. Dwivedi AN, Jain S, Dixit R. Gall bladder carcinoma: Aggressive malignancy with protean locoregional and distant spread. World J Clin Cases. 2015 Mar 16;3(3):231-44. doi: 10.12998/wjcc.v3.i3.231.

11. Gore RM, Yaghmai V, Newmark GM, Berlin JW, Miller FH. Imaging benign and malignant disease of the gallbladder. Radiol Clin North Am. 2002 Dec;40 (6): 1307-23, vi.

12. Haaga JR and Herbener EH. The gallbladder and biliary tract. In: Haaga JR, Lanzieri CF, Gilkeson RC (eds.). CT and MR Imaging of the whole body. (4th edn.) St Louis: Mosby; 2003;1357-60.

13. Afifi AH, Abougabal AM, Kasem MI. Role of multidetector computed tomography (MDCT) in diagnosis and staging of gall bladder carcinoma. The Egyptian Journal of Radiology and Nuclear Medicine 2013; 44(1):1-7. doi.org/10.1016/j.ejrnm.2012.12.006

14. George RA, Godara SC, Dhaga P. Computed Tomographic Findings in 50 Cases of Gall Bladder Carcinoma. Medical J Armed Forces 2007;63(3):215-9. doi: 10.1016/S0377-1237(07)80137-7.

\section{How to cite this article?}

Singh P, Kaur N, Kaur M. Spectrum of CT findings in gall bladder carcinoma patients in north Indian population. Int J Med Res Rev 2017;5(05):499-504. doi:10.17511/ijmrr. 2017.i05.11. 